\title{
The Protective Effect of Nigella sativa on Sperm Parameter in Mice treated with Dexamethasone
}

\author{
Saied Miri ${ }^{1}$, Morteza Abouzarypor ${ }^{2}$, Mohammad jafar Rezaie ${ }^{3}$, Fardin Fathi $^{4}$, Bahram Nikkho ${ }^{5}$, Daem \\ Roshani $^{6}$, Shiva Khalesro ${ }^{7}$, Erfan Daneshi ${ }^{8}$ \\ 1. MS.c. Cellular and Molecular Research Center, Research Institute for Health Development, Kurdistan University of \\ Medical Sciences, Sanandaj, Iran. ORCID ID: 0000-0001-7367-11x \\ 2. Assistant Professor, Cellular and Molecular Research Center, Research Institute for Health Development, Kurdistan \\ University of Medical Sciences, Sanandaj, Iran. ORCID ID: 0000-0002-5073-4171 \\ 3. Associate Professor, Department of anatomical sciences, School of Medicine, Kurdistan University of Medical Sciences, \\ Sanandaj, Iran. ORCID ID: 0000-0001-7332-1217 \\ 4. Professor, Cellular and Molecular Research Center, Research Institute for Health Development, Kurdistan University of \\ Medical Sciences, Sanandaj, Iran. ORCID ID: 0000-0002-4648-5598 \\ 5. Associate Professor, Department of pathology, School of Medicine, Kurdistan University of Medical Sciences, Sanandaj, \\ Iran. ORCID ID: 0000-0002-5050-793x \\ 6. Associate Professor, Department of Epidemiology and Biostatistics, School of Medicine, Kurdistan University of Medical \\ Sciences, Sanandaj, Iran. ORCID ID: 0000-0004-7461-114 \\ 7. Assistant Professor, Agronomy and plant breeding, department faculty of agriculture university of Kurdisan, Sanandaj, \\ Iran. ORCID ID: 0000-0003-3264-1673 \\ 8. Assistant Professor, Cellular and Molecular Research Center, Research Institute for Health Development, Kurdistan \\ University of Medical Sciences, Sanandaj, Iran., (Corresponding author), Tel: 087-33664658, E-mail: \\ erfan.daneshi@yahoo.com, ORCID ID: 0000-0003-3427-5478
}

\begin{abstract}
Background and Aim: Dexamethasone affects testis hemostasis through reduction of testosterone level. In one study dexamethasone induced spermatogenesis defects through epithelial vacuolizations and sloughing of germ cell layer.

Materials and Methods: Forty NMRI mice were randomly divided into four groups. Control and dexamethasone groups received normal saline and dexamethasone $(5 \mathrm{mg} / \mathrm{kg})$ respectively for 7 days. Dexamethasone and Nigella sativa(NS) $(5 \mathrm{mg} / \mathrm{kg})$ were given to the third group and the fourth group(Nigella sativa group) received $5 \mathrm{mg} / \mathrm{kg}$ Nigella sativa for 7 days. Epididymal sperm parameters were used for evaluation of the effects of dexamethasone and Nigella sativa on testis.

Results: Epididymal sperm parameters (count,motility and abnormal sperm) showed significant alterations in dexamethasone group $(\mathrm{p}<0.05)$. Treatment with $\mathrm{NS}+$ dexamethasone significantly prevented these changes $(\mathrm{p}<0.05)$.

Conclusion: Numerous studies have been performed to evaluate destructive effects of dexamethasone on male reproductive system. The aim of this study was to assess protective effect of Nigella sativa against the side effects of dexamethasone on male reproductive system. We found that dexamethasone could decrease sperm parameters. These changes were reduced by using Nigella sativa.
\end{abstract}

Keywords: Nigella sativa, Dexamethasone, Sperm parameters

Received: Sep 24, $2019 \quad$ Accepted: Dec 31, 2019

How to cite the article: Saied Miri, Morteza Abouzarypor, Mohammad jafar Rezaie, Fardin Fathi, Bahram Nikkho, Daem Roshani, Shiva Khalesro, Erfan Daneshi. The Protective Effect of Nigella Sativa On Sperm Parameter In Mice Treatment Dexamethasone. SJKU. 2020; 25 (3): 99-105

Copyright (C) 2018 the Author (s). Published by Kurdistan University of Medical Sciences. This is an open access article distributed under the terms of the Creative Commons Attribution-Non Commercial License 4.0 (CCBYNC), where it is permissible to download, share, remix, transform, and buildup the work provided it is properly cited. The work cannot be used commercially without permission from the journal 


\section{بررسى اثر محافظتى سياهداذه بر بار امتر هاى اسپرم در موشهاى سورى تيمار شده با دونزامتازون}

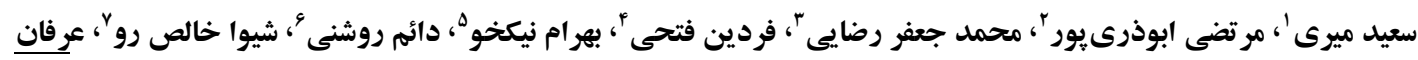

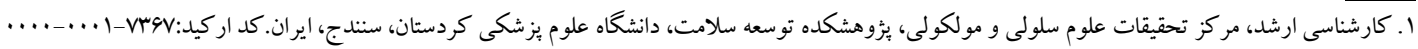

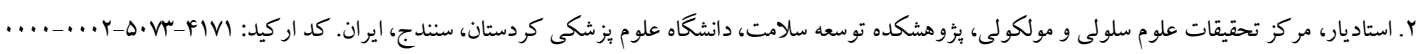

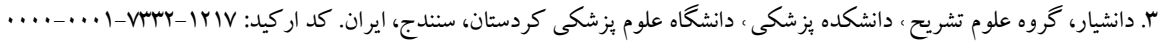

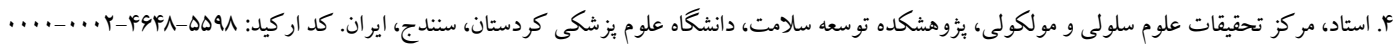

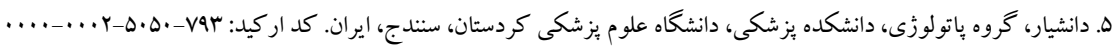

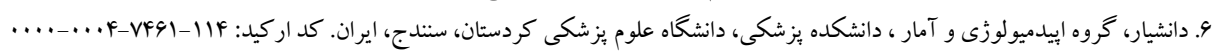

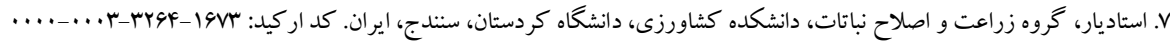

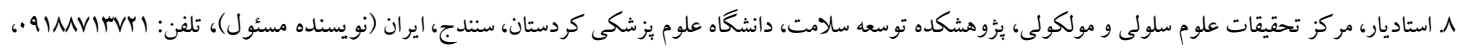
يست الكترونيك: Erfan.daneshi@yahoo.com، كد اركيد:

جكيده

زمينه و هدف: دگزامتازون بر روى هموستاز بيضه، از طريق كاهش سطح تستوسترون تاثير مى گذارد، در مطالعهاى نشان دادند

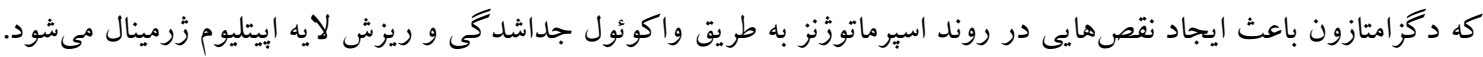

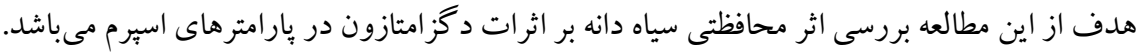

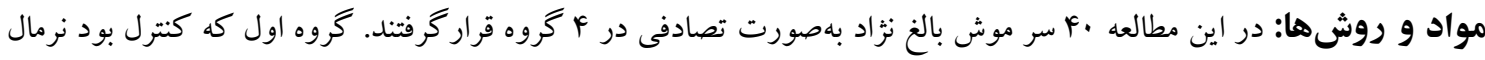

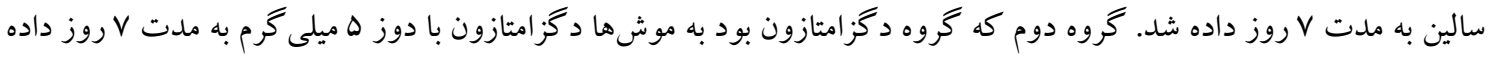

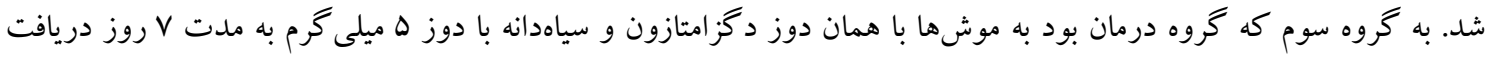

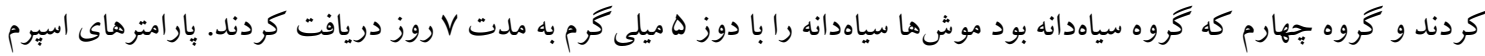
جهت بررسى دگزا امتازون و سياهدانه انجام شد.

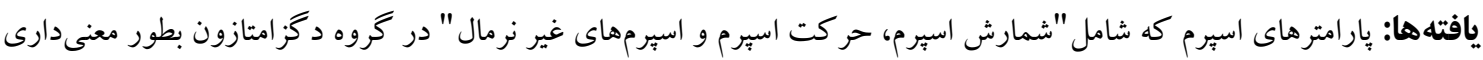

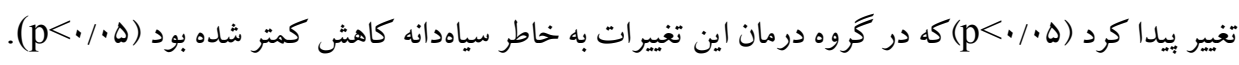

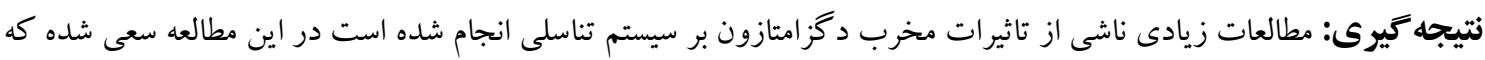

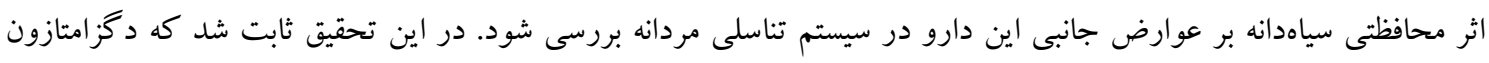

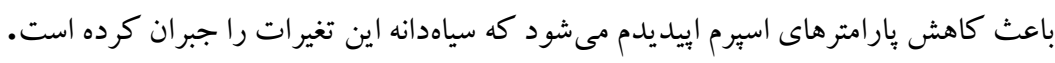

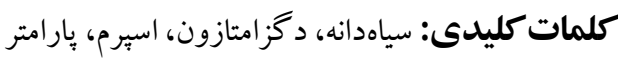

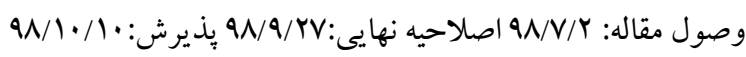


در اين مطالعه •F سر موش بالغ نزاد NMRI (موسسه

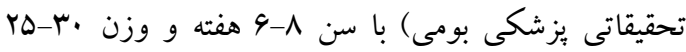

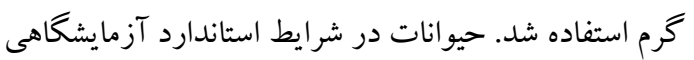

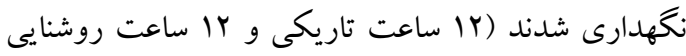

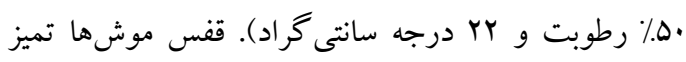

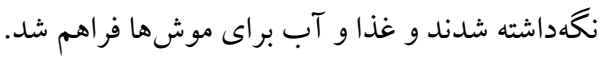

$$
\text { انجام آزمايش }
$$

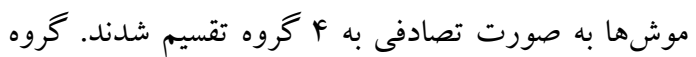
اول كه كنترل بود نرمال سالين به مدت V V روز داده شد.

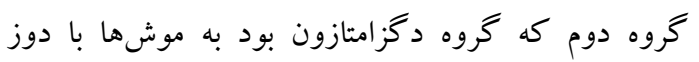

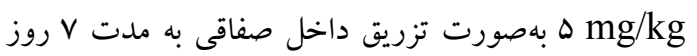
دززامتازون داده شد(rا). به گروه سوم كه گروه درمان

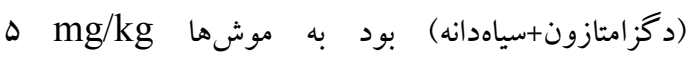

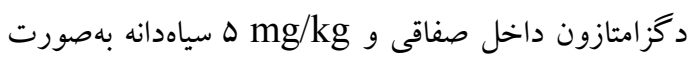

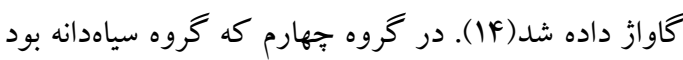

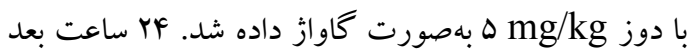
از تزريق آخرين دوز، موشها به طريق جابجايى مهرههاى كردنى قربانى شدند.

$$
\text { يار إمترهاى اسيرم }
$$

بعد از قربانى كردن موشها به طريق جا به جايى مهرههاى

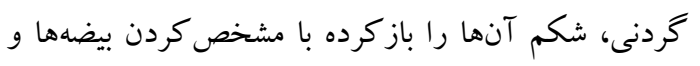

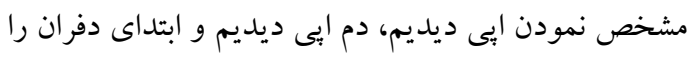

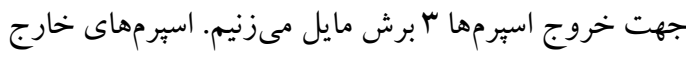

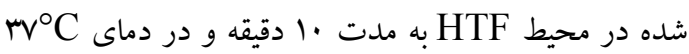

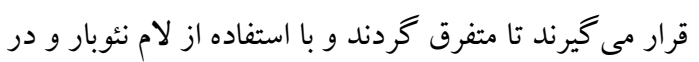

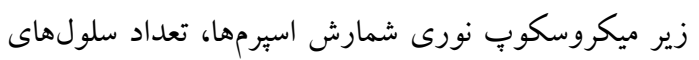

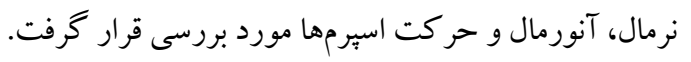

يافتهها در اين بررسى بارامترهاى سيمن از نظر تعداد اسبرم، انواع

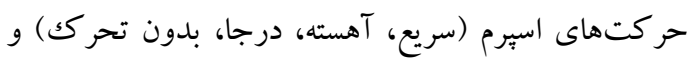

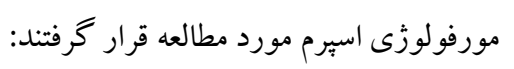

اسيرماتوزنز فر آيند بسيار بيجيده و منحصر به فرد است كه منتهى به تشكيل اسبرماتوزوئيدها مىشود، عوامل متعددى بهري

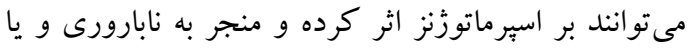

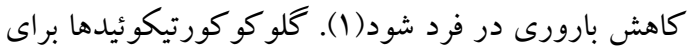
حيات ضرورى هستند و نقشهاى كليدى در متابوليسم، سيستم ايمنى و مغز ايفا مى كنند(Y). كلو كو كورتيكوئيدها

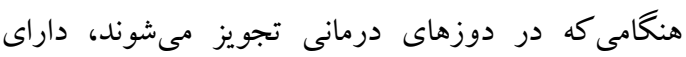
اثرات قوى ضد التهابى و سركوبخر ايمنى هستند(ب).

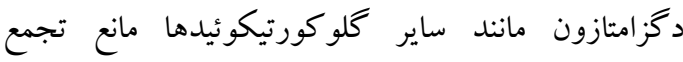
سلولهاى التهابى از جمله ماكروفازها و لكوسيت ها در مارد محل التهاب شده و از فاكوسيتوز و آزادشدن آنزيمهاى ليزوزومى جلو گيرى مى كند و بدون تأثير بر علل التهاب باعث كاهش واكنشهاى بافتى در روند التهاب مى شود (F).

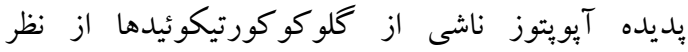
بيولوزيكى و كلينيكى بسيار با اهميت است(ه). دُخز امتازون

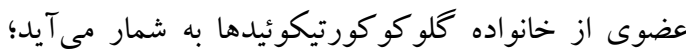

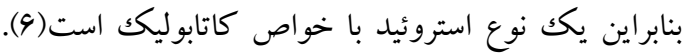

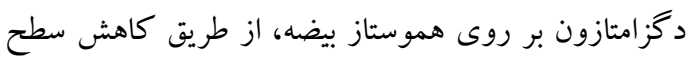
تستوسترون تأثير مى گذارد(V)، در مطالعهاى نشان دادند كه

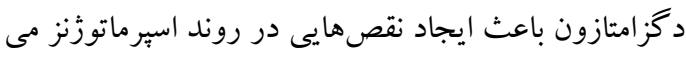

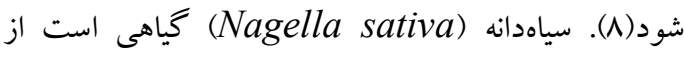
خانواده آلاله كه اثرات متعدد درمانى بر آن شناخته شده است(ه). اين گياه در طب سنتى بسيارى از كشورها استفاده الداه

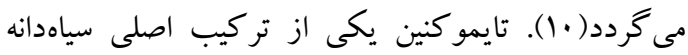
است كه داراى خاصيت آنتى اكسيدانى است(11). مطالعات قبلى اثر محافظتى سياهدانه را بر اثرات سمى موادى مثل بيس اديس

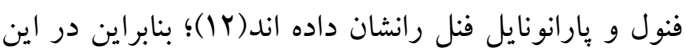
مطالعه با توجه به اثرات مخرب د گز امتازون و استفاده آن در

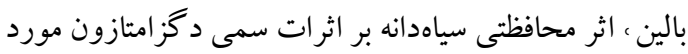

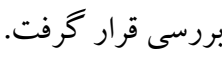

مواد و روشها 
دخزامتازون) اين كاهش جبران شد و تعداد اسيرمها افزايش

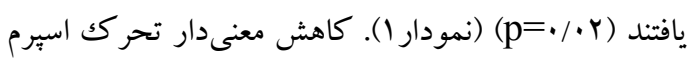
و افزايش معنىدار اسبرمهاى غير نرمال در گرووه دريافت

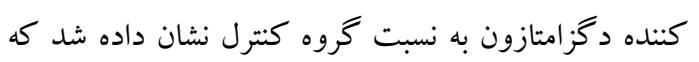

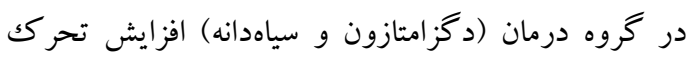

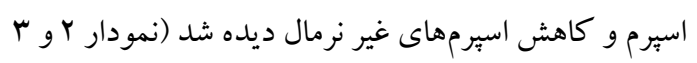
. $(p<\cdot / \cdot \Delta)($

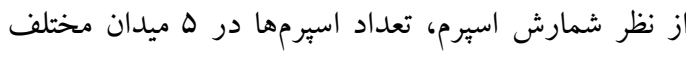
ميكروسكوب نورى در هر موش مورد بررسى قرار گرفتند.

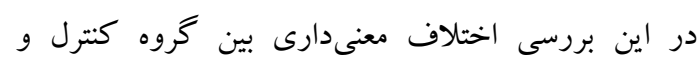

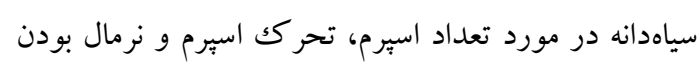

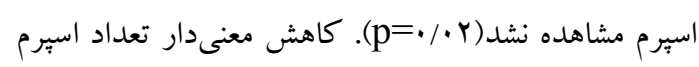

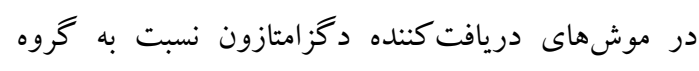
كنترل نشان داده شد كه در گروه درياف درمان (سياهدانه و

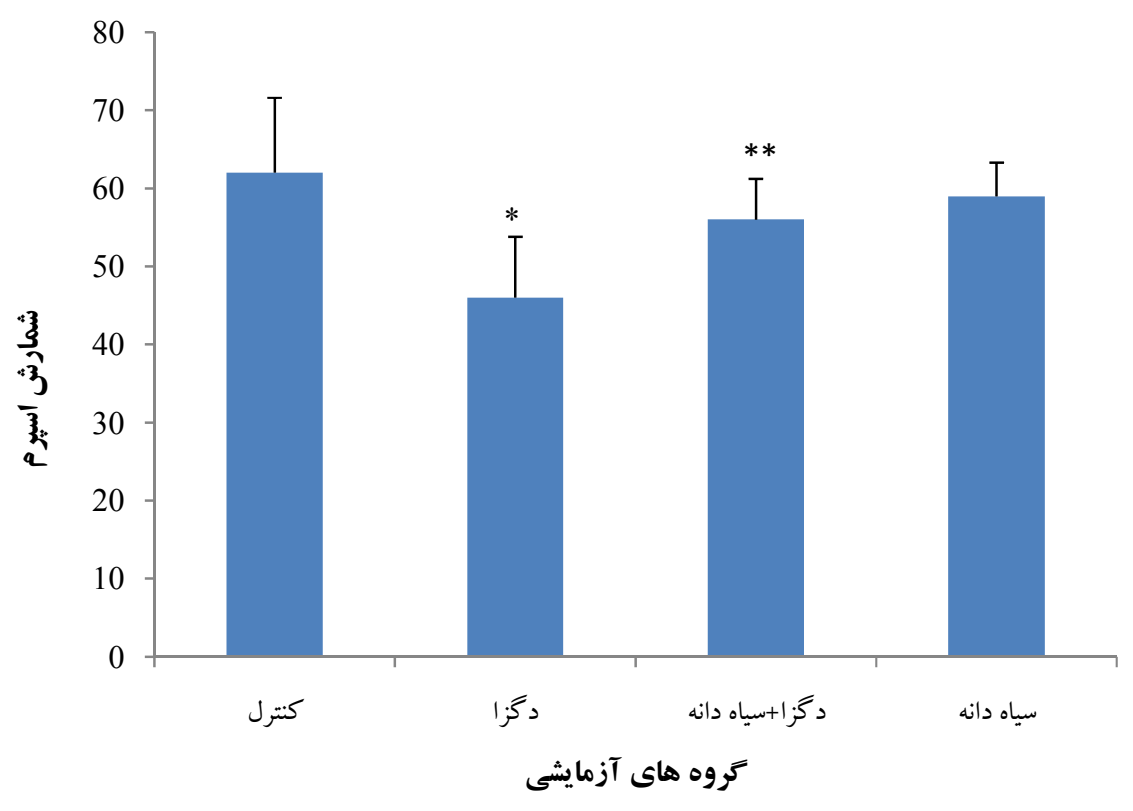

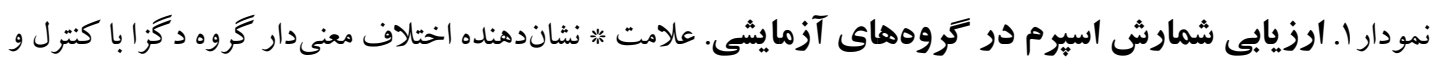

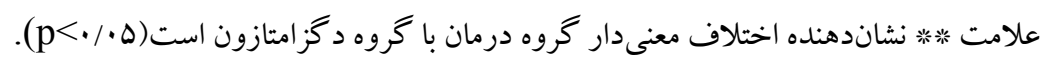




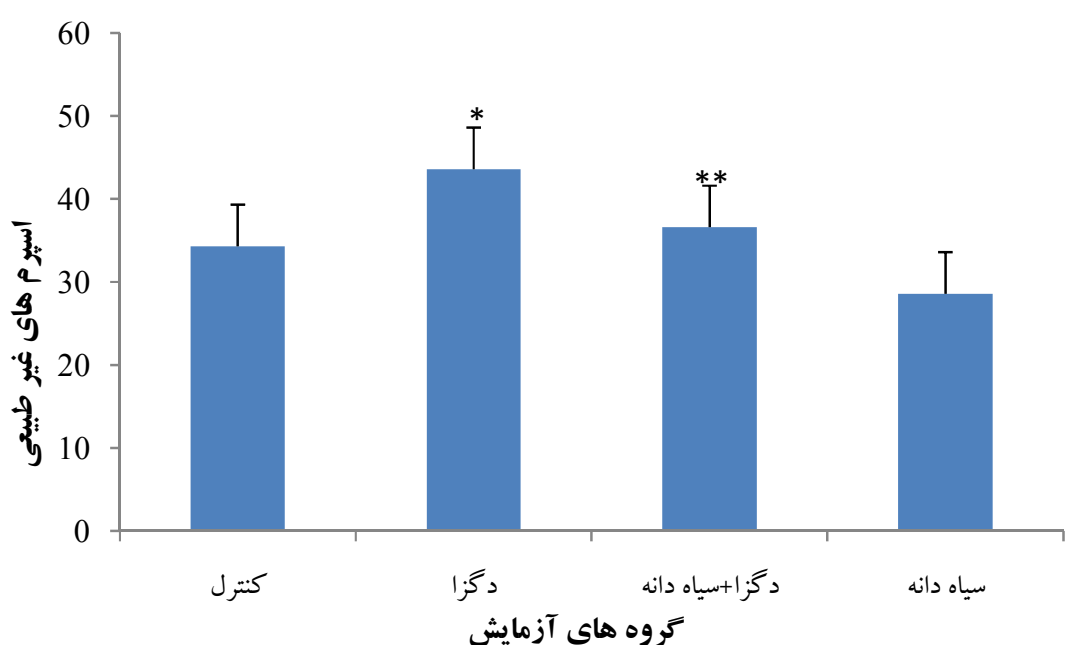

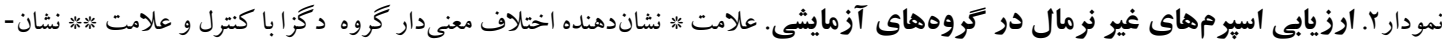

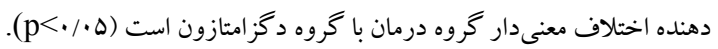

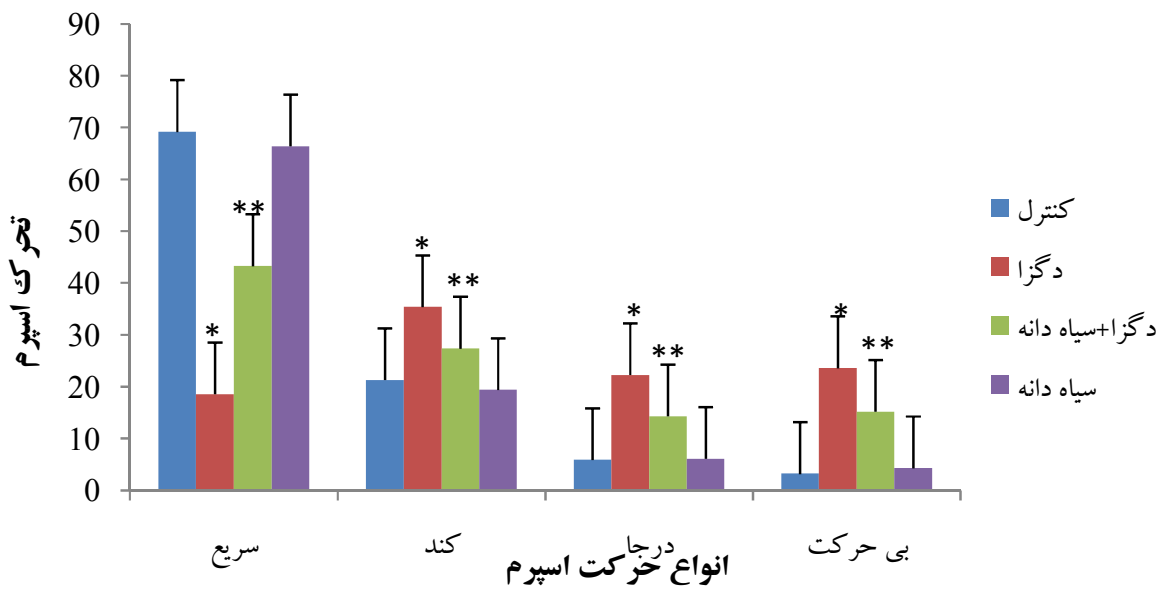

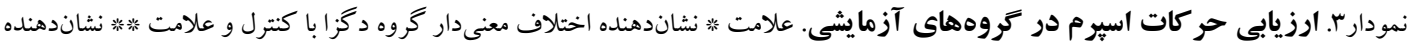

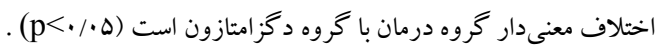

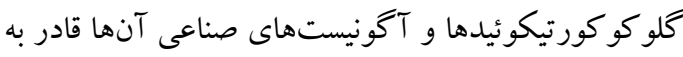

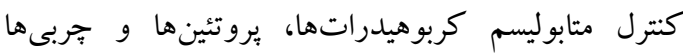

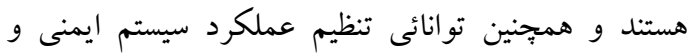
دستگاه قلب و عروق را دارا مىباشند. گلو كو كورتيكوئيدها

با كاهش سطح تستوسترون اسبرماتوزنز را مختل مى مى

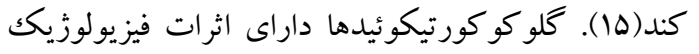
متعدد و گستردهاى هستند. آنها بر روى متابوليسم

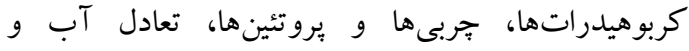

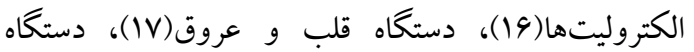
مطالعات زيادى ناشى از تأثيرات مخرب دگزامتازون بر سيستم تناسلى انجام شده است در اين مطالعه سعى شده است كه اثر محافظتى سياهدانه بر عوارض جانبى اين دارو

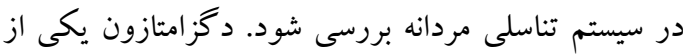
يرفروشترين داروها در سراسر دنيا محسوب مىشود. اين دارو جزء دسته داروهاى كلوكوكورتيكوئيدى است.

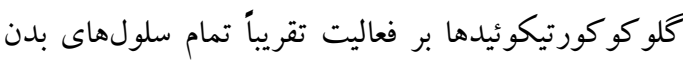

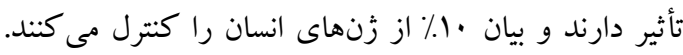


متوجه شدند كه تجويز تيتانيوم باعث كاهش بارامترهاى

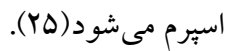

Gao و همكارانش (Y...r) در تحقيقات خود نشان دادند كه افزايش در غلظت كلو كو كورتيكوئيدهاى كاهش تعداد سلولهاى ليديگك مىشود (צا). در اين تحقيق همجِين مشخص شد كه سياهدانه به طور مؤثرى باعث افزايش شمارش اسبرم و كاهش اسبرمهاى غيرطبيعى مىشود كه بيانكر اثرات مفيد سياهدانه است. سليمانى و همكاران

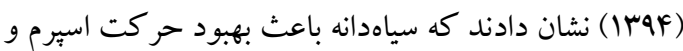
افزايش حيات اسبرم مىشود(YV) در اين مطالعه بارامترهاى استرم توسط سياهدانه تغييرات مثبتى داشته است؛ كه مشابه تحقيقات Ghlissi و همكاران (Y • Y) بود كه ثابت كردند سياهدانه باعث بهبود حركت اسبرم و افزايش حيات اسيرم

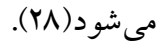

\section{نتيجه كيرى} مطالعه حاضر نشان داد كه دكزامتازون اثرات مخرب بر سيستم تناسلى و كاهش بارورى دارد. سياهدانه به عنوان يكك عامل محافظتى مىتواند در كاهش اين اثرات منفى د دززامتازون نقش داشته باشد.

تشكر و قدردانى

بودجه اين تحقيق كه حاصل باياننامه كارشناسى ارشد سعيد

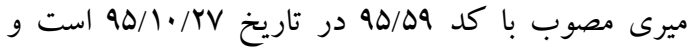
محل انجام طرح آزمايشكاه سلولى و مولكولى دانشكده يزشكى دانشكاه علوم يز شكى استان كردستان بوده است. اين طرح از محل اعتبارات معاونت يُزوهشى دانشكاه علوم

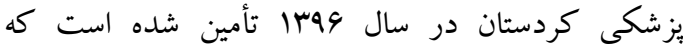
بدينوسيله از اين معاونت تشكر مى گردد.

ايمنى(1))، استخوان(19) و تشكيل عناصر خونى(·r) تأثير دارند. Chris و همكارانش (4..r) گزارش دادند دگزامتازون باعث ايجاد آيويتوز در نورونهاى دانهاى مخجِه در رت مىشود. آنها متوجه شدند Y ساعت بِ إس از تجويز دگزامتازون كاسِاز-r و عامل القاءكننده آيويتوز

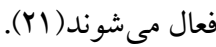
اسيرماتوذنز فرآيندى كاملاً وابسته به هورمون به ويزه تستوسترون است و بديهى است هر گونه تغيير در ميزان اين هورمون مىتواند در اسبرماتوزنز مؤثر باشد. Nadies و همكارانش (1999) با استفاده از EDS (اتان-دى متانسولفانات) كه يك ماده سمى براى سلولهاى ليديخك است، سلولهاى ليديگك را از بين بردند و در نتيجه سطوح

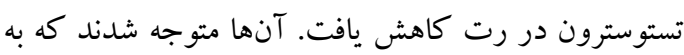

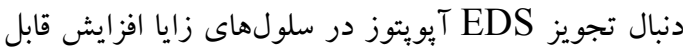

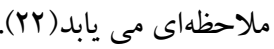
در اين مطالعه نشان داديم كه دگزامتازون باعث كاهش تعداد اسيرمها، حر كت اسيرم و بدشكلى اسيرمها مى شود كه اين نتايج مشابه نتيجه تحقيق fioratti و همكاران (Y. Y (Y)

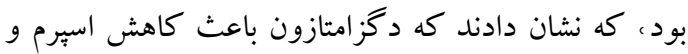
كاهش حركت بيشرونده و سرعت اسبرم و در نهايت

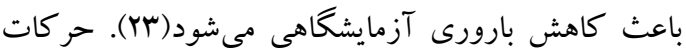
اسبرم مىتواند تأثيرى باشد بر اثر مواد مخرب بر بر بردي

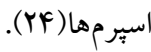
اسيرماتوزنز فرآيندى كاملاً وابسته به هورمون به ويزّه

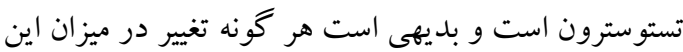
هورمون مىتواند در اسبرماتوزنز مؤثر باشد. در مطالعهاى

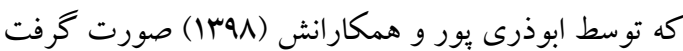

منابع

1. Nudel D, Monoski M, Hipshultz L. Common medication and drug how they affect male fertility. Urol Clin North Am .2002; 29(4), 965-73. 
2. Oppong E, Cato A. Effects of Glucocorticoids in the Immune System. Adv Exp Med Biol. 2015;872:217-33. 3. Iyalomhe G, Iyalomhe SI. Current use of corticosteroids in rheumatology. Int Res J Pharm Pharmacol. 2013; 3(6):85-90.

4. Pitter JN, Flower RJ. The adrenal cortex. Pharm. 2007; 427-436.

5. Jia W, Wu J, Jia H, Yang Y, Zhang X, Chen K, et al. The peripheral blood neutrophil-to-lymphocyte ratio is superior to the lymphocyte-to-monocyte ratio for predicting the long-term survival of triple-negative breast cancer patients. PLoS One. 2015;10(11).

6. Sean CS, Paul SB. the complete drug reference. Pharm Press. 2007;421-439.

7. Orr TE, Mann DR. Role of glucocorticoid in the stress induced suppression of testicular steroidogenesis in adult male rats. Horm Behav. 1992; 26: 350-363.

8. Khorsandi L, Mirhoseini M, Mohamadpour M, Orazizadeh M, Khaghani S.Effect of curcumin on dexamethasone-induced testicular toxicity in mice. Pharm Biol. 2013;51(2):206-12

9. Mohammed T I, Bishwajit G, Thoufiqul A, Sarrin S Nigellalogy: A Review on Nigella Sativa. MOJ. 2017;3(6): 00056

10. Shafiq H, Ahmad A, Masud T, Kaleem M. Cardio-pro tective and anti-cancer therapeutic potential of Nigella sativa. Iran J Basic Med Sci. 2014;17(12):967-79.

11. Zeinab S ,Badlishah Sham B,Hossein B. Antioxidant Property, Thymoquinone Content and Chemical Characteristics of Different Extracts from Nigella sativa. J Am Oil Chem Soc. 2014; 91(2): 295-300.

12. Shariatzadeh MA, Hajian Karahroodi A. Evaluation of the effect of Nigella sativaoil on sperm parameters in adult NMRI mice treated with Bisphenol A. AMUJ. 2015; 17(93): 47-5.

13. Chrysis D, Ritzen E M and Sävendahl L. Growth retardation induced by dexamethasone is associated with increased apoptosis of the growth plate chondrocytes. J Endocrinol.2003;176, 331-337.

14. Ait Mbarek L, Ait Mouse H, Elabbadi N, Bensalah M, Gamouh A, Aboufatima et all.. Antitumor properties of blackseed (Nigella sativa L.) extracts. Braz J Med Biol Res. 2007; 40 (6): 839 - 47.

15. Julia CB. Glucocorticoids, exemplars of multi-tasking. Br J Pharmacol 2006; 147:258-268.

16. Munk A, Guyre PM, Holbrook NJ. Physiological functions of glucocorticoids and their relation to pharmacological actions. Endor Rev. 1984; 5: 25-44.

17. Pearl JM, Nelson DP, Schwartz SM. Glucocorticoids reduce ischemia-reprefusion-induced myocardial apoptosis in immature hearts. Ann Thorac Surg. 2002; 74: 830-836.

18. Jondal M, Pazirandeh A and Okret S. A role for glucocorticoids in the thymus. Trends Immunol. 2001; 22: 185-189.

19. Canalis E, Delany AM. Mechanism of glucocorticoid action in bone. Acad Sci. 2002; 966: 71-73.

20. Chauhan S, Leach CH, Kunz S, Bloom JW and Miesfeld RL. Glucocorticoid regulation of human eosinophil gene expression. Mol Biol. 2003; 84: 441-452.

21. Chris M, Minh T, Terje R, Jon L, Ragnhild P. Dexamethasone induces cell death which may be blocked by NMDA receptor antagonists but is insensitive to $\mathrm{Mg} 2+$ in cerebellar granule neurons. Brain Res Brain Res Rev. 2006; 1070: 116-123.

22. Nandi S, Partha P, Zirkin BR. Germ cell apoptosis in the testes of Sprage Dawley rats following testosterone withdrawal by ethane 1, 2-dimethanesulfonate administration: relationship to Fas?. Biol Reprod. 1999; 61: 70-5. 23. fioratti E, Villaverde A, Meli C, Tsunemi M, Papa F, Avarenga M, Infiunce of steroid anti inflammatory drugs on viability and fertility of eqiun semen. $\mathrm{j}$ equin e vet sci. 2012;32 771-5.

24. El-Demerdash FM, Yousef MI, Kedwany FS, Baghdadi HB. Role of $\alpha$-tocopherol and $\beta$-carotene in ameliorating the fenvalerate-induced changes in oxidative stress, hemato-biochemical parameters, and semen quality of male rats. J Environ Sci Health. 2004;39:443-59.

25. Abouzaripour, M, Hosaini Bae, M, Rezaie, M.J, Nikkho, B., ,Khalesro, S.H,Daneshi, E.et al. Protective effect of Nigella sativa on sperm parameters in mice exposed to titanium dioxide during embryonic developme.Scientific Journal of Kurdistan University of Medical Sciences. 2019; 60: 461-470.

26. Gao HB, Tong MH, Hu HY, You HY, Guo QS, Ge RS, Hardy MP. Mechanism of glucocorticoid-induced Leydig cell apoptosis. Mol Cell Endocrinol. 2003; 199: 153-63.

27. Soleimani MM, Shariatzadeh S, Azadpour M. Protective effect of Nigella sativa oil on the Bisphenol A induced-testicular toxicity in adult mice NMRI. Journal of cell\& tissue. 2015; 6 : 87 - 96

28. Ghlissi Z, Hamden K, Saoudi M, Sahnoun Z, Zeghal KM, El Feki A, et al. Effect of Nigella sativa seeds on reproductive system of male diabetic rats. Afr J Pharm Pharmacol. 2012;6:1444-50A 